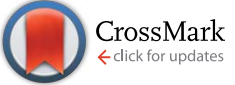

Cite this: RSC Adv., 2016, 6, 111380

\title{
Green synthesis of Ag nanoparticles in large quantity by cryomilling $\dagger$
}

\begin{abstract}
Nirmal Kumar, ${ }^{a}$ Krishanu Biswas ${ }^{* a}$ and Raju Kumar Gupta ${ }^{b}$
Most of the synthetic methods for the preparation of Ag nanoparticles (Ag NPs) involve wet chemical synthesis, in which hazardous chemicals are used and the NPs are further stabilized by a surfactant. The presence of a surfactant is detrimental to the purity as well as to the native properties of the Ag NPs. The present study reports a unique technique to prepare ultrapure free-standing Ag NPs in large quantities without the use of any hazardous chemicals. This has been achieved by cryomilling. Note that cryomilling is a cost effective method to prepare metal NPs, involving ball milling below $160 \pm 10^{\circ} \mathrm{C}$ under a protective Ar atmosphere. The experimental results reveal that it is possible to obtain Ag NPs with a narrow size distribution $(4-8 \mathrm{~nm}$ ). The level of contamination (34 ppb of $\mathrm{W}$ ) in the nanoparticles was estimated by EPMA, whereas the ultra-high purity of the Ag NPs was confirmed by ICP-OES and XPS. The surfactant-free Ag NPs were also stable at elevated temperatures $\left(400{ }^{\circ} \mathrm{C}\right)$ and exhibited freestanding nature in liquids including ethanol, methanol, and water. The results have been discussed based on the low-temperature deformation behaviour of $\mathrm{Ag}$ and the electrostatic stabilization of highly pure $\mathrm{Ag}$ NPs in different polar liquids.
\end{abstract}

Received 16th September 2016 Accepted 7th November 2016

DOI: 10.1039/c6ra23120a

www.rsc.org/advances itself should be designed to utilize and generate substances that possess little or no toxicity to human health and the environment. $^{3}$ There are few reports on the green synthesis of $\mathrm{Ag}$ NPs. ${ }^{4-20}$ Some of the reports utilized the seed extract of Calendula officinalis, ${ }^{4}$ Capsicum annuum L., ${ }^{5}$ and many other plants $^{6-9}$ to minimize the use of hazardous Ag-salts in the preparation of Ag NPs. In some cases, template-based sputtering has been utilized to produce Ag NPs over the surfaces with narrow size distributions, however, limited yields of the NPs were obtained. ${ }^{\mathbf{1 0 - 1 2}}$ Also, there are reports on the mechanochemical syntheses to prepare Ag NPs, in which mechanical milling along with the simultaneous reduction of silver nitrate occurred $\left(\mathrm{Ag}^{+} \rightarrow \mathrm{Ag}^{0}\right) \cdot{ }^{13-19}$ However, these methods utilized the reduction of $\mathrm{Ag}^{+}$to obtain $\mathrm{Ag}$ NPs and most importantly, the yields of the Ag NPs obtained using these methods was low. ${ }^{13-19}$ Moreover, the reduction of $\mathrm{Ag}^{+}$to $\mathrm{Ag}$ NPs involves the use of hazardous chemicals. A detailed literature survey reveals that the most notable example of a green synthesis of $\mathrm{Ag}$ NPs involved the arc discharge of bulk $\mathrm{Ag}^{.20}$ This synthesis consumes bulk silver rods at $100 \mathrm{mg} \mathrm{min}^{-1}$ and yields an 11 to $19 \mathrm{ppm}$ concentration of $\mathrm{Ag}$ NPs along with $\mathrm{Ag}^{+}$ions. However, the bulk silver and Ag NPs are later separated by centrifugation (18 $000 \mathrm{rpm}$ for $100 \mathrm{~min}$ ), ${ }^{20}$ and thus, they also suffer from lack of size control during the synthesis. Almost all the techniques, reported to date, have not been able to produce Ag NPs with ultra-high purity. In summary, the existing eco-friendly methods have various limitations including low yields, the use of surfactants to stabilize the as-synthesized NPs, oxidation and agglomeration of the NPs etc. ${ }^{21}$ Most importantly, 
nanoparticles prepared by eco-friendly methods are stabilized by a layer of surfactant, which limits the native properties of the NPs. ${ }^{6,7}$ Moreover, these techniques are not suitable for the preparation of metal NPs in large quantities. However, the requirement of metal NPs is extensive, and thus, it is important to devise methods to prepare NPs in large quantities.

The present study reports a novel green synthesis technique to prepare ultrapure metal NPs, especially Ag NPs, in large quantities. It is well known that pure Ag NPs exhibit superior antibacterial properties..$^{22,23}$ In addition, Ag NPs find applications in catalysis ${ }^{24}$ colorimetric detection of melamine in milk, ${ }^{25}$ as enhanced fluorescence markers ${ }^{26,27}$ etc. Note that the use of a surfactant to stabilize the Ag NPs has a detrimental effect on the native properties of the NPs as the surfactants cover the surface of the NPs and thereby, reduce the effectiveness of the NPs.

Cryomilling, a top-down approach, involving high energy ball milling ${ }^{28-34}$ at low temperature $\left(-160 \pm 10^{\circ} \mathrm{C}\right)$ under an inert atmosphere, is reported to be capable of producing metal nanoparticles in large quantities. In conventional cryomilling, the silver powder is mixed with $\mathrm{LN}_{2}$ (liquid nitrogen) to achieve a low temperature during ball milling and this makes, the preparation of highly pure metal NPs by this method a challenge. Herein, we demonstrate the preparation of Ag NPs of ultra-high purity (impurity < $35 \mathrm{ppb}$ ) using a novel custom-built cryomill, in which the powder does not come in contact with $\mathrm{LN}_{2}{ }^{35}$ In addition, it is possible to prepare $\mathrm{Ag}$ NPs in large quantities (60-70 g per day) in a single ball mill. In the presentstudy, we describe the synthesis of ultra-high pure Ag NPs via a green synthesis, avoiding the use of hazardous chemicals. Here, $\mathrm{LN}_{2}$ is used for cooling the silver powder and milling media. Note that $\mathrm{LN}_{2}$ quickly evaporates in the form of $\mathrm{N}_{2}$ gas, which comprises approximately $78 \%$ of the air that we breathe. Thus, the reported preparation of the Ag NPs does not leave any hazardous waste products. This technique does not require any hazardous chemicals, reducing agents or even capping agents for the preparation as well as stabilization of the Ag NPs. The nanoparticles do not get contaminated during the synthesis processes, such as oxidation, nitridation, or though the debris from the milling tools. The preparation of the Ag NPs has been demonstrated using different materials characterization techniques (XRD, SEM, TEM, EPMA, ICP-OES, XPS). The $\mathrm{Ag}$ NPs remained stable up to $400{ }^{\circ} \mathrm{C}$ even in the absence of capping agents or surfactants. Thus, the availability of surfactant-free native $\mathrm{Ag}$ NPs provides novel functionalization opportunities, which would never be achieved for chemically synthesized powders.

\section{Experimental details}

\section{Synthesis of Ag nanoparticles}

The green synthesis of free-standing Ag nanoparticles was carried out by cryomilling using powder of $99.9 \%$ purity (Alpha Aesar, USA; -325 mesh). A custom-built single ball cryomill has been utilized. The cryomill was cooled below $-160 \pm 10^{\circ} \mathrm{C}$ using liquid nitrogen $\left(\mathrm{LN}_{2}\right.$ boiling temperature $\left.-196{ }^{\circ} \mathrm{C}\right)$. The details of the mill design have been reported elsewhere. ${ }^{35}$ The ball mill was designed in such a way that liquid nitrogen does not come in contact with the powder during the milling process. Therefore, milling was always performed in a dry state. The milling was carried out under an inert gas atmosphere by purging Ar gas (1 litre per $h$ ) through the milling chamber, and the temperature of the powder was continuously monitored using a K-type thermocouple. A ball to powder ratio of $80: 1$ was used for milling using a single tungsten carbide (WC) ball. The milling was carried out for $7 \mathrm{~h}$ and the powder was intermittently collected (at $30 \mathrm{~min}$ intervals) for structural as well as microstructural analyses. Sufficient care was taken to avoid any type of contamination while handling the powder.

\section{Characterization}

X-ray diffraction patterns of the synthesized powders were obtained ( $\mathrm{Cu} \mathrm{K} \alpha$ radiation, $\lambda=0.154056 \mathrm{~nm}, 2 \theta$ range of $20-100^{\circ}$ ) using a Bruker D8 Focus diffractometer. The crystallite sizes and micro-strain were calculated from the peak broadening using the Hall-Williamson approach. ${ }^{36}$ The particles size distributions were obtained using transmission electron microscope (FEI, Titan $\mathrm{G}^{2} 60$ operated at $300 \mathrm{kV}$ ). The cryomilled powder was dispersed in pure methanol followed by ultrasonication and dispersed using a micropipette on a carbon coated $\mathrm{Cu}$ grid, which was dried overnight prior to the TEM observation. The purity of the nanoparticles was studied using an electron probe micro-analyzer (EPMA, JXA-8230, JEOL, Tokyo, Japan). Trace metal contamination through the debris from the milling tool was estimated by inductively coupled plasma-optical emission spectrometer (ICP-OES, Thermo scientific, Inc., iCAP 6300, spectrometer). The cryomilled powder, acid digested $\left(\mathrm{HNO}_{3}\right)$ with minimal heating, and possible contaminants (arising from the milling tools) were estimated. The oxidation and nitridation of the NPs were investigated by X-ray photoelectron spectroscopy (PHI 5000 Versa Prob II, FEI Inc.). The binding energies in the XPS patterns were estimated in reference to the $\mathrm{C} 1 \mathrm{~s}$ peak $(284.8 \mathrm{eV})$ of the surface adventitious carbon. The zeta potential was obtained using Malvern zetasizer Nano ZS90 apparatus. All measurements were carried out at $25{ }^{\circ} \mathrm{C}$ with a field strength of $60 \mathrm{~V} \mathrm{~cm}^{-1}$. $\mathrm{pH}$ measurements were performed using a pH meter (Mettler Toledo FE20).

\section{Results}

\section{X-ray diffraction (XRD)}

The as-received silver powder (Alfa Aeser, USA, particles size < $40 \mu \mathrm{m}$ ) was cryomilled for up to 7 hours and the samples were collected intermittently (after every 30 minute) for X-ray diffraction analysis. The XRD patterns for the cryomilled powder are shown in Fig. 1a [the inset showing the (200) peak]. All the peaks in the patterns have been consistently indexed using reflections due to FCC silver (lattice parameter, $a=$ $0.40862 \mathrm{~nm}$ ). To the best of the resolution of XRD, there was no evidence of oxidation and nitridation. The figure (inset) shows the broadening of the peaks during cryomilling, and thus, the peak broadening was used to calculate crystallite size as well as 

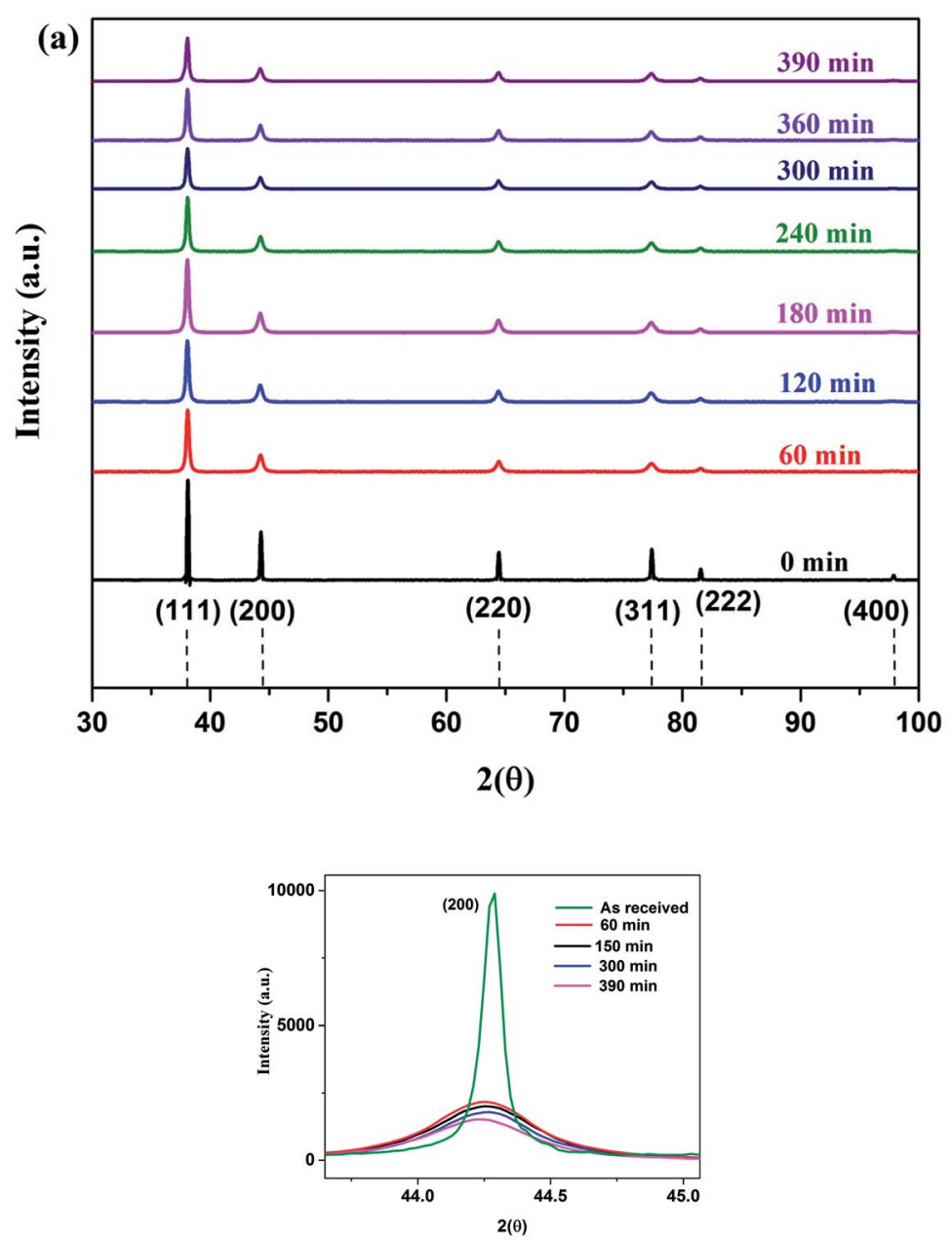

Inset

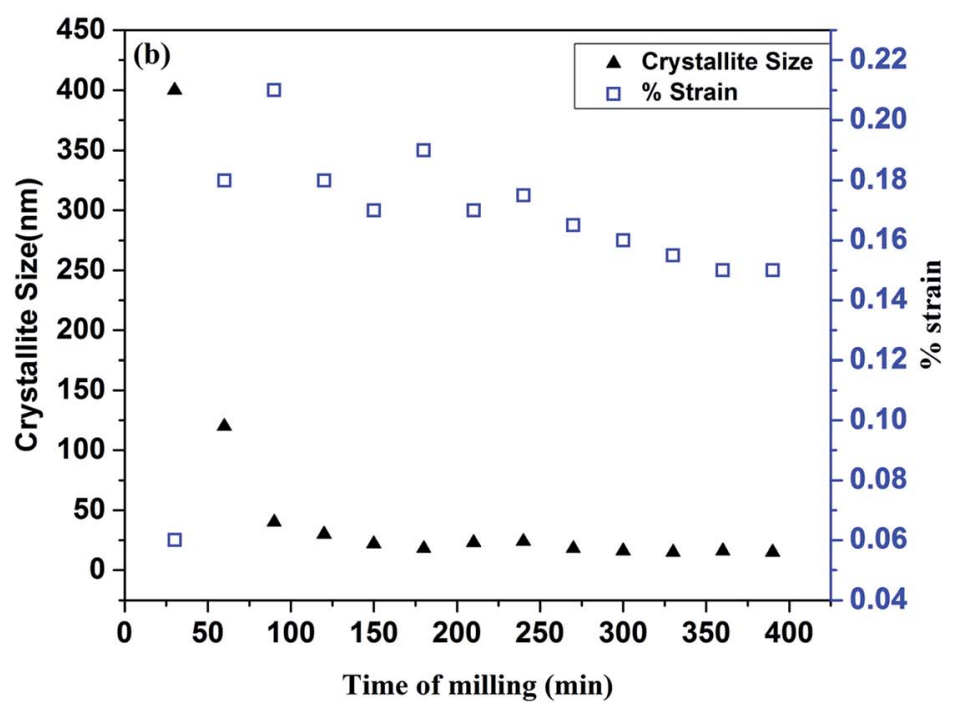

Fig. 1 (a) X-ray diffraction pattern of the Ag cryomilled powder; the inset shows the enlarged (200) peaks from the unmilled and milled powder, indicating broadening; (b) variation of crystallite size and strain with time of milling.

strain. The crystallite size and strain variation with the milling time were evaluated using the Hall-Williamson approach ${ }^{36}$ after subtracting the instrumental peak broadening. Fig. $1 \mathrm{~b}$ reveals the crystallite size and microstrain as a function of the milling time. It shows that the crystallite size of the Ag NPs steadily varies from 6-8 $\mathrm{nm}$ after 7 hours of milling. First, the 
microstrain rapidly increased as shown Fig. 1b. Then, it stabilized as the particle sizes reached the lowest value. In addition, the crystallite size, measured using the Hall-Williamson method, was further corroborated by the TEM study. Consequently, it was possible to prepare Ag NPs with a narrow size distribution by cryomilling. ${ }^{35}$ There are several processing parameters, including the ball to powder ratio (BPR), milling time, milling temperature, type of ball mills, shapes of milling vials, milling speed, milling media, number of balls etc., that affect the nanoparticle size and size distribution of the $\mathrm{Ag}$ NPs. ${ }^{37,38}$ However, it is possible to set the process parameters in such a way that the Ag NPs of different crystallite sizes (bigger or smaller) can be prepared. Thus, the present synthesis technique is indeed versatile.

\section{Electron microscopy analysis (size and morphology)}

To obtain finer scale microstructural information (shape and size distribution), the milled powder was investigated using FESEM and TEM. Fig. 2 shows the FESEM image of the asreceived silver powder, which have a spherical shape and wide size distribution. To evaluate the precise shape and size of the cryomilled powder, TEM was carried out. A typical TEM (bright field) micrograph is shown in Fig. 3a. The particles have an approximate spherical shape with a narrow size distribution (as indicated in Fig. 3c). The histograms have been generated using at least 500 nanoparticles observed in the bright field TEM micrographs and analyzed using Image $^{39}$ software. In this process, the threshold contrast was applied to filter out the background noise. Moreover, the black areas in the processed image were calculated as the diameter of the NPs and the average particle size was $6 \pm 2 \mathrm{~nm}$. Fig. 3b shows a high resolution image of one such nanoparticle with the inset showing the FFT (Fast Fourier Transform). The as-prepared Ag NPs quite were stable up to $400{ }^{\circ} \mathrm{C}$. Based on the in situ TEM studies, it has been reported that the $\mathrm{Ag}$ NPs start to coalesce at $200{ }^{\circ} \mathrm{C}$ and form micron-sized particles even after 30 minutes of annealing treatment. ${ }^{39,40}$ Herein, annealing of the surfactant-free Ag NPs at

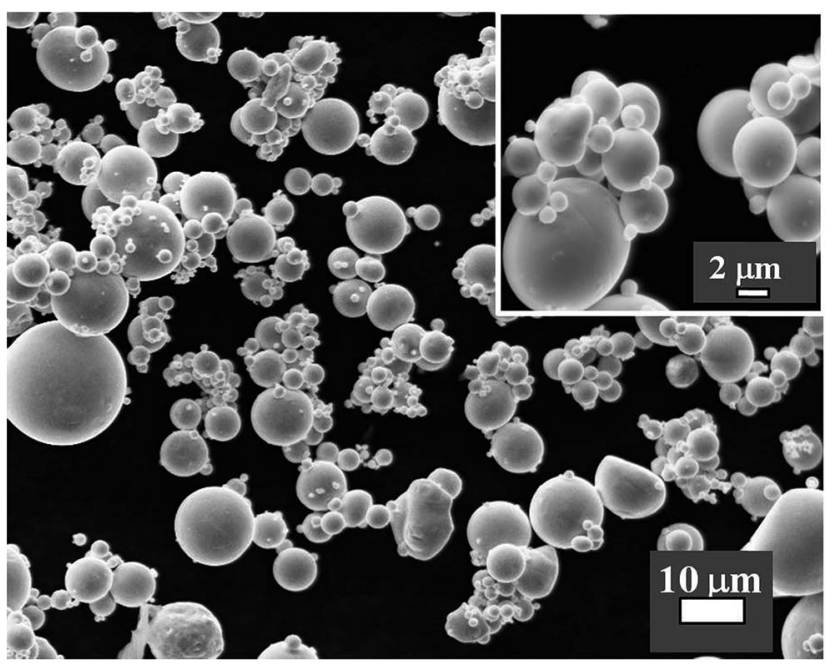

Fig. 2 FESEM images of the as-received silver powder. different temperatures (350 and $400{ }^{\circ} \mathrm{C}$ ) was carried out for 2 hours to systematically study the stability of the NPs. The results indicate that the Ag NPs were stable up to $350{ }^{\circ} \mathrm{C}$ (see ESI $\dagger$ ).

\section{Purity of the nanoparticles}

The purity of the Ag NPs is the most important factor for their use in many applications. Depending upon the level of contamination, the properties of the nanoparticles get altered. It has already been reported that cryomilling can be used to prepare high purity metal nanoparticles for their use in a variety of applications. ${ }^{35}$ We have utilized different characterization tools to determine the purity of the as-synthesised Ag NPs. The purity was first investigated using an electron probe micro analyzer (EPMA, detection limit in ideal condition $\sim 10 \mathrm{ppm}$ ). As shown in Fig. 4, the EPMA could not detect any elements other than $\mathrm{Ag}$ and C. Carbon was present due to the carbon tape utilized for mounting the powder sample. Further, the trace element (contamination) was investigated using inductively coupled plasma-optical emission spectrometry (ICP-OES) with a detection limit of $>0.1 \mathrm{ppb}$. The cryomilled powder ( 7 hours) contained $34 \mathrm{ppb} \mathrm{W}$, which is very low when compared to that obtained by conventional ball milling. ${ }^{41}$ The nanoparticles are also prone to oxidization and nitridation during the synthesis. Therefore, the possibilities of oxidation and nitridation were investigated using X-ray photoelectron spectroscopy (XPS) with a detection limit of 0.01 atom\%. Fig. 5a displays the survey spectra for the cryomilled silver powder, which displayed only $\mathrm{Ag}, \mathrm{C}$ and $\mathrm{O}$ peaks with no evidence of nitrogen. All the peaks were referenced according to adventitious carbon at $284.8 \mathrm{eV}$. The oxygen peaks at $530.97 \mathrm{eV}$ and $532.64 \mathrm{eV}$, as shown in Fig. $5 \mathrm{c}$, can be attributed to oxygen adsorbed on the surface and $\mathrm{H}_{2} \mathrm{O} /-\mathrm{OH}$, respectively, ${ }^{\mathbf{4 2 - 4 6}}$ which are due to an exposure to the environment while handling the powder after cryomilling. The peaks at $368.02 \mathrm{eV}$ and $374.02 \mathrm{eV}$ can be attributed to the $3 \mathrm{~d}_{5 / 2}$ and $3 \mathrm{~d}_{3 / 2}$ binding energies of $\mathrm{Ag}^{0}$, respectively. A similar study was carried out for the Ag NPs annealed at different temperatures. The details are available in the ESI. $\dagger$ Selected area electron diffraction (SAED) analysis indicates that the crystal structure of the annealed Ag NPs was the same as that of the asreceived and cryomilled Ag powders. XPS analysis lead to a similar conclusion reported earlier for the cryomilled powder. In addition, the oxygen content in the annealed and cryomilled Ag NPs was measured and compared with that of the as-received powder. The $\mathrm{O}$ content exhibited an increasing trend in the assynthesized Ag NPs (12.13 atom\%) and annealed Ag NPs (13.80 atom\%) when compared to that of the as-received power $(10.46$ atom\%). This was mainly due to an increase in the surface area of the nanoparticles. Consequently, oxygen adsorbed on the surface increased due to exposure to the environment while handling the powder. Therefore, it is evident that the annealed powder was not oxidized and the $\mathrm{O}$ peaks were due to the surface adsorbed oxygen.

\section{Stability in polar solvents}

To confirm the free-standing nature of the Ag NPs, the cryomilled powder was dispersed in ultra-pure ethanol, followed 

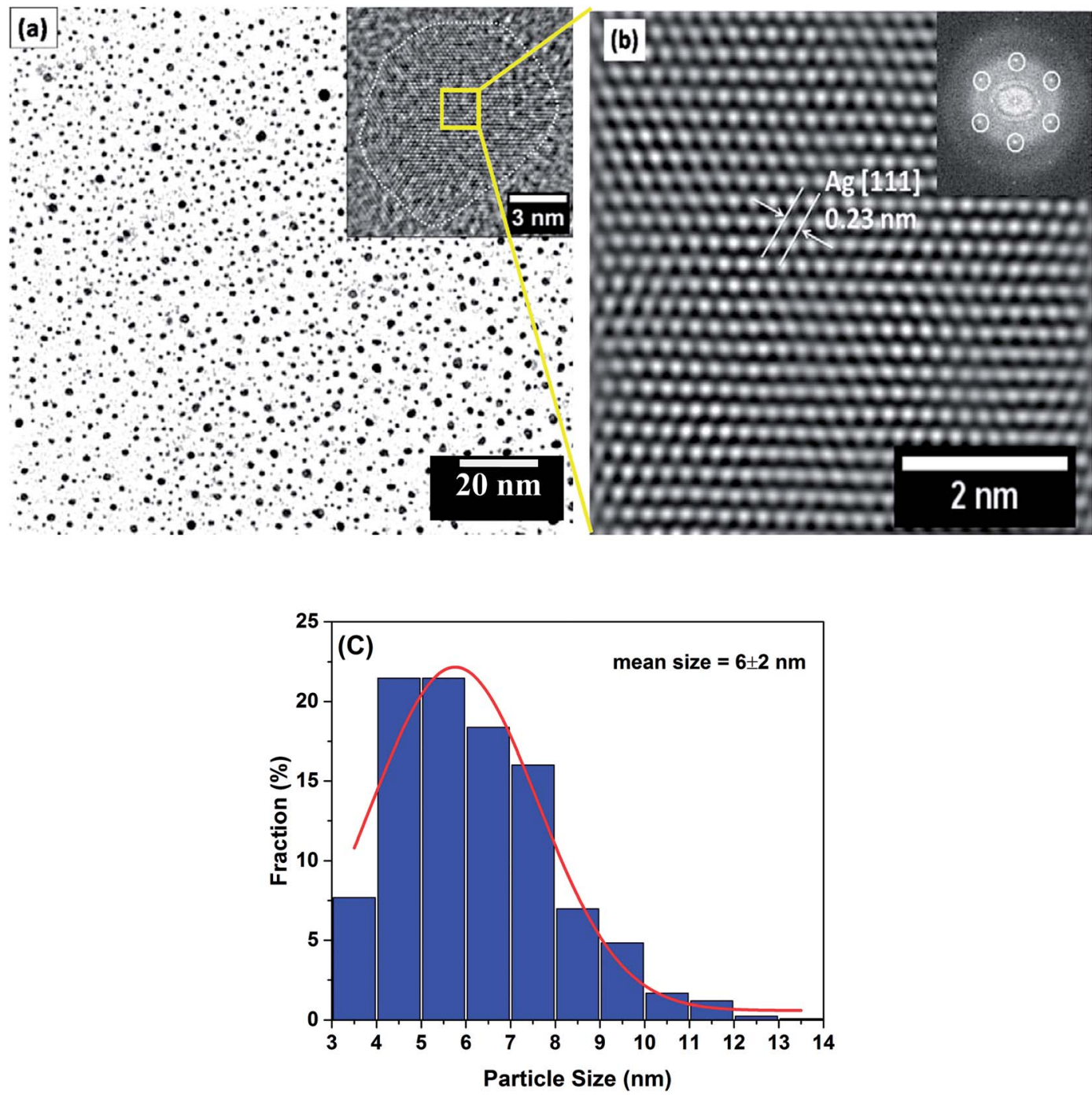

Fig. 3 (a) Bright field TEM micrograph of the silver nanoparticles after 7 hours of cryomilling, (b) a high resolution image of the Ag nanoparticles and the inset shows FFT; (c) a histogram of nanoparticles distribution.

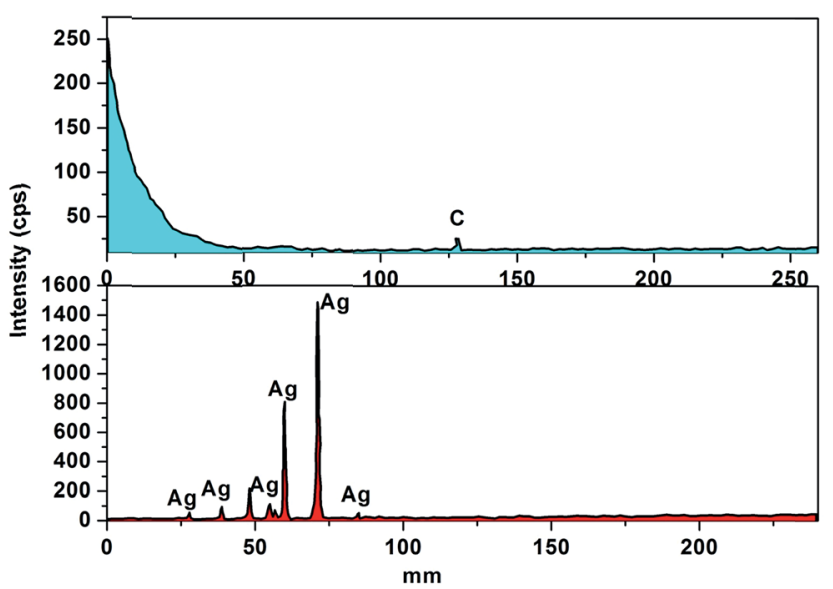

Fig. 4 EPMA spectra of the silver cryomilled powder (carbon from the LDE crystal and Ag from the PET crystal). by ultrasonication. The Ag NPs were quite stable in ethanol due to their nanosize as well as the surfactant free native surfaces. Therefore, the Ag NPs remained dispersed in the solvent for a longer time (for several weeks). This was due to the electrostatic stabilization of the NPs in the polar solvent, which lead to an electric equilibrium between the NPs and solvent, as shown in Fig. 6a. In addition, the NPs acquired a surface charge in the solvent and the surface charge as well as the diffusion layer surrounding the Ag NPs formed an electrical double layer.

The potential at slipping plane (zeta potential) decided the stability of a dispersion, where the strong electrical charge at the slipping plane kept them apart through repulsive forces. In case of the Ag NPs, the zeta potential was measured at different $\mathrm{pH}$ values, as shown in Fig. 6b. Initially, upon the addition of $\mathrm{OH}^{-}$ions, the value of zeta potential decreased reaching $-17 \mathrm{mV}$ at $\mathrm{pH} 7$, where the dispersion exhibited the highest stability; however, at higher $\mathrm{pH}$, the value of zeta potential decreased. This may be due to the surface saturation of the 

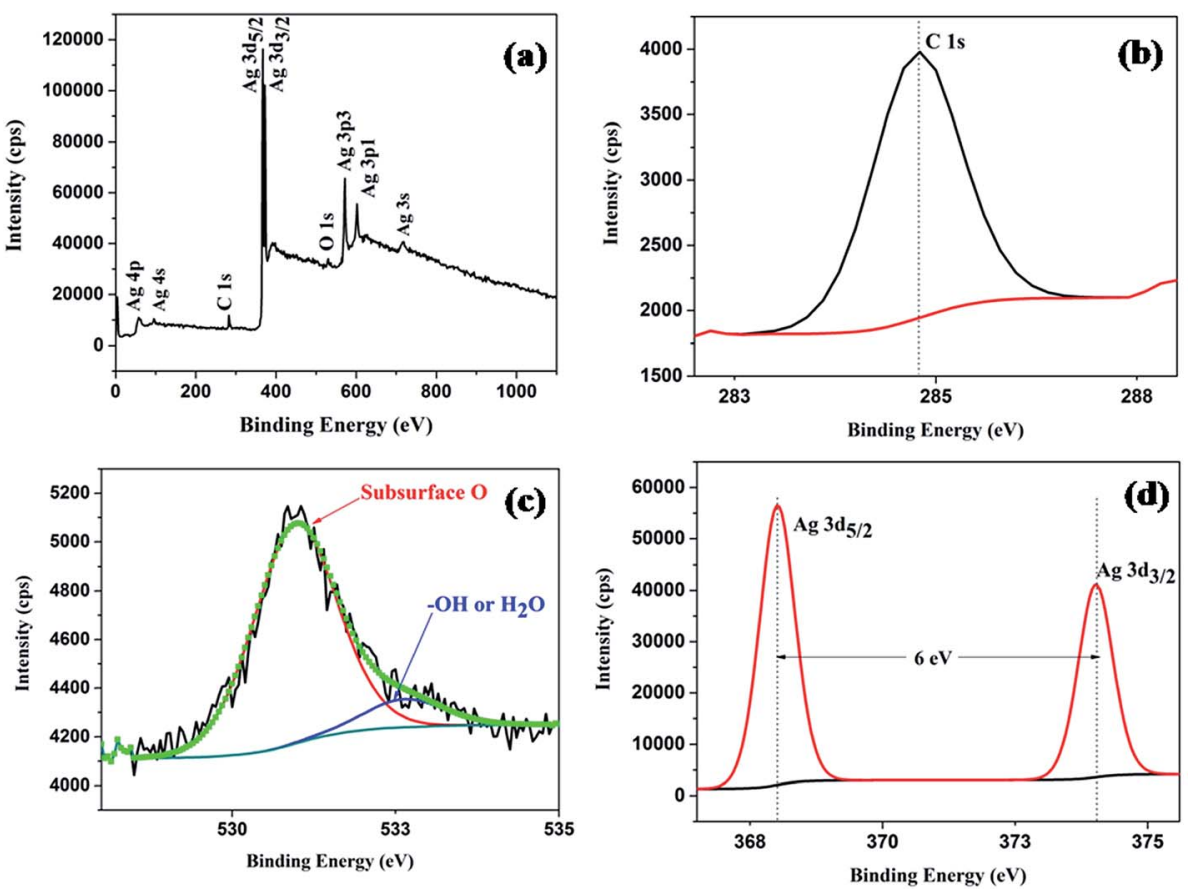

Fig. 5 XPS spectra of the cryomilled powder after 7 hours of cryomilling: (a) survey spectra of silver, (b) C 1s, (c) $O 1$ s and (d) Ag $3 d$.
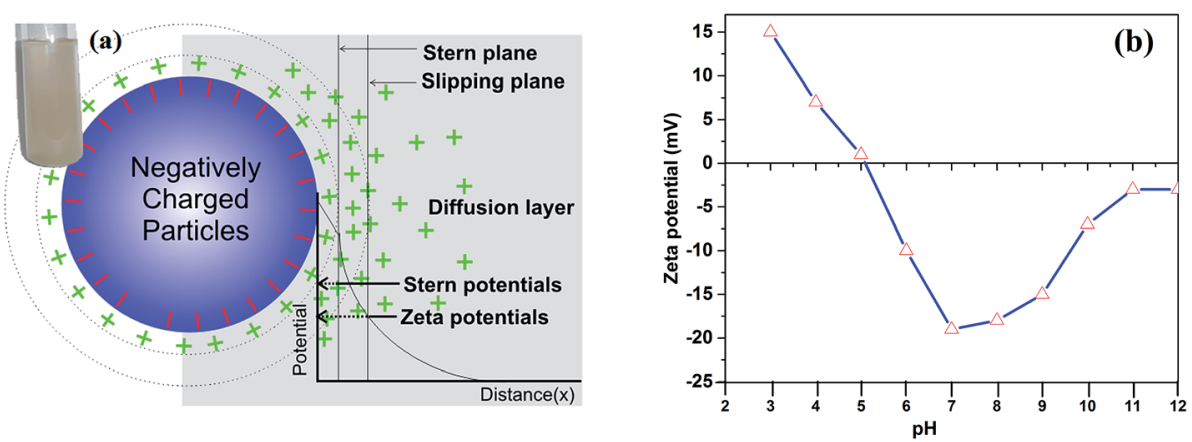

Fig. 6 (a) Schematic for the Stern model of electric double layers; ${ }^{36}$ (b) the zeta potential as a function pH for the Ag NPs dispersed in ethanol.

particles and excess $\left(\mathrm{OH}^{-}\right.$ions) charge working against the stability of the dispersion. ${ }^{47}$ The Ag NPs with native surfaces were highly sensitive in the basic medium and got oxidized in an excess of $\mathrm{NH}_{4} \mathrm{OH}$ solution. Therefore, they were likely to form unstable $\mathrm{AgOH}$. In the absence of any capping agent, they can even form a soluble complex with ammonia, as shown below. ${ }^{48}$

$$
\mathrm{AgOH}+2 \mathrm{NH}_{3}=\mathrm{Ag}\left(\mathrm{NH}_{3}\right)_{2} \mathrm{OH}
$$

The formation of the complex at the nanoparticles surface was easy due to the virgin/native surface at higher $\mathrm{pH}$. Moreover, this lead to a decrease in the value of the zeta potential and the flocculation process dominated. Therefore, it is important to note that the ultra-pure Ag NPs with virgin surfaces exhibit a free-standing nature at neutral $\mathrm{pH}$ (see $\mathrm{ESI} \dagger$ ).

\section{Discussion}

The increasing demands and public interest for the nanomaterials put our ecosystem at risk ${ }^{49}$ due to the use of hazardous chemicals during their synthesis and stabilization. Almost all the high purity metal NPs, reported to date, had been synthesised using hazardous chemicals. Ag NPs, utilized in various applications, are predominantly synthesized via wet chemical routes, which require hazardous precursors and reducing agents. Since, cryomilling does not utilize any hazardous chemicals, the present synthesis technique is considered a green process. $\mathrm{LN}_{2}$ was poured in the specially designed reservoir (surrounding of the milling chamber) to maintain extremely low temperature ${ }^{35}$ during the ball milling process. Subsequently, these NPs have been found to exhibit a free-standing nature in different polar liquids. There are two important aspects in this study: the preparation of the free- 
standing Ag NPs during cryomilling and the stabilization of the $\mathrm{Ag}$ NPs in different liquids.

In general, mechanical milling is a process in which powders are charged in a vial along with balls, which are then subjected to collide with each other as well as with the powder. During the process, the powder particles are repeatedly flattened, coldwelded, fractured, and re-welded. ${ }^{22,23}$ However, during cryomilling, the powder is cooled to an extremely low temperature $\left(<-150^{\circ} \mathrm{C}\right)$. Cryomilling takes advantages of both the extremely low temperature (achieved through liquid nitrogen) and those associated with the conventional ball milling. Cooling of the milling media and powders is an effective approach to suppress the recovery and recrystallization and accelerate the fracture process leading to finer grain structures and more rapid grain refinement. Fundamentally, the preparation of free-standing nanoparticles is decided by the competition between the coldwelding and fracturing phenomena during the ball milling. Low temperatures will accelerate the fracturing of the materials, including Ag by decreasing the fracture toughness as well as the ductility of Ag. Notethat the cold-welding phenomena of the metallic material is also sensitive to the milling temperature. Cooling down to a very low temperature is an effective mean to accelerate the fracturing process for the metallic materials. ${ }^{50}$ Thus, cryomilling increases the number of fracturing events and suppresses the cold-welding. Although some cold-weld might form during the process of milling, however, these welds will not have sufficient strength. This lead to an early grain refinement and consequently, the formation of nanoparticles in a short milling time. The process of early grain refinement also reduced the debris formation from the milling tools due to the shorter milling time and thus, it ensured the high purity of the nanoparticles. Additionally, metal contracted as the temperature was reduced because of the anharmonic atomic vibration about their mean positions. Consequently, this lead to a decrease in the interatomic spacing. This, in turn strengthened the restoring forces and lead to an increase in the Young's modulus. ${ }^{51}$ Therefore, metal powder particles were easily fractured with high impact during cryomilling.

An extremely low temperature ensured the formation of ultra-refined Ag NPs (6-8 nm). Although, the finer particles with high surface energy were prone to oxidation during synthesis; the low temperature and inert atmosphere inside the ball mill ensured contamination free nanoparticles with native surfaces. Therefore, these nanoparticles with virgin/native surfaces are efficient as catalysts due to their high specific active surface area. ${ }^{52}$ In almost all of the wet chemical synthesis of Ag NPs, reported to date, capping agents have been efficiently utilized to obtain agglomeration free nanoparticles. In these processes, the NPs were stabilized due to their steric interactions with the capping agent. ${ }^{53}$ Interestingly, the Ag NPs, synthesized using cryomilling were agglomeration free as well exhibited a freestanding nature in different polar liquids (water, ethanol, methanol etc.) because the Ag NPs are electrostatically stabilized in the solvent. ${ }^{53,54}$ The Ag NPs were found to be stable and well-dispersed in ethanol due to their nanosizes and native surfaces. The surfactant-free nanoparticles were observed to be stable for weeks. These nanoparticles with virgin surfaces were easily polarized when in contact with the polar solvent molecules. The Ag NPs easily acquired a surface charge at the nanoparticles/solvent interface and subsequently, an electrostatic equilibrium was reached between the nanoparticles and solvent. ${ }^{53}$ In other words, an electrical double layer was formed surrounding an individual NP and this lead to electrostatic repulsion between the Ag NPs. The said stabilization is called electrostatic stabilization, ${ }^{53}$ where two types of forces such as the force of attraction (closer forces with significant and very short distances; particles almost touch to operate this force) and electrostatic repulsion (longer distance forces) operate. Here, gravity was considered to have a negligible effect due to the extremely small size of the nanoparticles. The Brownian motion of the NPs can make them collide with each other all the time in a solvent. A combination of the van der Waals attractive forces and electrostatic repulsion forces acted on the NPs. When NPs came closer, they repelled each other due to their similar charges. If the repulsive force between them dominates, the resulting energy barrier develops a little away from the surface of the NPs (see ESI $\dagger$ ). The kinetic energy produced by the Brownian motion will not be sufficient to allow the NPs to cross the barrier if the barrier height is more than $10 \mathrm{kT}$, where $k=$ Boltzmann constant and $T=$ absolute temperature. Thus, the NPs remained well-dispersed for a longer time and exhibited a free standing nature. The zeta potential (potential at slipping plane) of the $\mathrm{Ag} \mathrm{NPs}(-17 \mathrm{mV}$ at $\mathrm{pH} 7)$ indicated the free-standing nature of the Ag NPs in ethanol. Similar studies in methanol and water confirmed the free-standing nature of the Ag NPs.

Another important characteristic of the cryomilling technique is that it is possible to synthesize Ag NPs in large quantities. It is well-known that surfactant-free NPs can find applications as catalysts, flexible displays, nano-fluids, sensors etc., therefore, a huge requirement of the NPs exists in the niche market, which can be fulfilled through their preparation by cryomilling. In the following, we shall provide an estimate on the synthesis of Ag NPs by cryomilling. It has been categorically shown that cryomilling can produce metallic nanoparticles of ultra-high purity. Detailed study indicated that the yield of the Ag NPs obtained by this process was about $97 \%$. About $3 \%$ of the total milled powder was lost as it got coated on the ball and vials during the process. However, this helped in preventing a direct contact between the powder and the milling tools. The custom-built cryomill ${ }^{35}$ [250 cc vial and $150 \mathrm{cc}$ ball] can accommodate $24 \mathrm{~g}$ of silver with a $40: 1$ ball to powder ratio (BPR). It takes about 7 hours to obtain Ag NPs with sizes below $10 \mathrm{~nm}$. Thus, $70 \mathrm{~g}$ of Ag NPs can be synthesized per day. This amount was significantly large when compared to that obtained by the earlier reported green synthetic techniques such as chemical synthesis, ${ }^{55}$ arc discharge ${ }^{20}$ and plasma induced chemical synthesis. ${ }^{56}$ Moreover, it is possible to prepare high purity Ag NPs in kilograms quantity using cryomilling on an industrial scale. In addition, electrostatically stabilized Ag NPs will open up new vistas to study the controlled aggregation, leading to self-organization mechanisms useful for many applications including plasmonics sensors. The present method can be an easily implemented industrially viable 
manufacturing process. Overall, the cryomilling process will allow the preparation of different metal NPs via an environmentally friendly and low cost technique, which is accessible to even non-specialist users.

\section{Conclusion}

In summary, cryomilling is capable of preparing ultrapure $\mathrm{Ag}$ metal nanoparticles without the use of any hazardous chemicals. Moreover, contamination of the milled powder was successfully reduced in this process. Thus, this preparation technique is a fully green process when compared to other techniques. In particular, the following conclusions can be drawn:

(i) Cryomilling lead to the refinement of the Ag NPs (4-8 nm) with a yield of $97 \%$ when compared to conventional ball milling. The yield of the Ag NPs was very high when compared to that obtained using other techniques.

(ii) Low temperature accelerated the fracturing process resulting in particles of ultra-high purity (contamination $<35$ $\mathrm{ppb}$.

(iii) The nanoparticles exhibited free-standing nature in different polar liquids and were stable up to $400{ }^{\circ} \mathrm{C}$.

(iv) It is possible to scale up the process for commercial production.

(v) The formation and stabilization of the ultra-pure freestanding Ag NPs has been explained based on the low temperature deformation behaviour of $\mathrm{Ag}$ and electrostatic stabilization in different liquids.

\section{Acknowledgements}

The authors would like to acknowledge the financial support provided by the SERB-DST, India and also thankfull Advanced Imaging Center, IIT Kanpur for TEM results.

\section{References}

1 N. R. Jana, L. Gearheart and C. J. Murphy, Chem. Commun., 2001, 7, 617-618.

2 R. Shankar, B. B. Wu and T. P. Bigioni, J. Phys. Chem. C, 2010, 114, 15916-15923.

3 P. Wasserscheid, Handbook of Green Chemistry Green Solvents: Ionic Liquids, ed. Peter Wasserscheid and Annegret Stark, Wiley-VCH-Verlag, 2010, vol. 6, ch. 1, pp. 4-5.

4 A. Baghizadeh, S. Ranjbar, V. K. Gupta, M. Asif, S. Pourseyedi, M. J. Karimi and R. Mohammadinejad, J. Mol. Liq., 2015, 207, 159-163.

5 S. Li, Y. Shen, A. Xie, X. Yu, L. Qiu, L. Zhang and Q. Zhang, Green Chem., 2007, 9, 852-858.

6 K. Vijayaraghavan, S. P. K. Nalini, N. U. Prakash and D. Madhankumar, Colloids Surf., B, 2012, 94, 114-117.

7 B. Ajitha, Y. Ashok Kumar Reddy and P. Sreedhara Reddy, Powder Technol., 2015, 269, 110-117.

8 M. J. Ahmed, G. Murtaza, A. Mehmood and T. M. Bhatti, Mater. Lett., 2015, 153, 10-13.
9 V. K. Sharma, R. A. Yngard and Y. Lin, Adv. Colloid Interface Sci., 2009, 145, 83-96.

10 F. Ruffino and M. G. Grimaldi, Appl. Surf. Sci., 2013, 270, 697-706.

11 F. Ruffino and M. G. Grimaldi, J. Appl. Phys., 2011, 110, 044311.

12 L. Zhang, F. Cosandey, R. Persaud and T. E. Madey, Surf. Sci., 1999, 439, 73-85.

13 T. Jayaramudu, G. M. Raghavendra, K. Varaprasad, G. V. S. Reddy, A. B. Reddy, K. Sudhakar and E. R. Sadiku, J. Appl. Polym. Sci., 2016, 133, 43027.

14 B. Lu, F. Zhan, G. Gong, Y. Cao, Q. Zhen and P. Hu, RSC Adv., 2016, 6, 74662-74669.

15 M. J. Rak, T. Friscic and A. Moores, RSC Adv., 2016, 6, 5836558370.

16 G. R. Khayati and K. Janghorban, Adv. Powder Technol., 2012, 23, 808-813.

17 V. Kumar and S. K. Yadav, J. Chem. Technol. Biotechnol., 2009, 84, 151-157.

18 J. X. Wang, Q. X. Zhang, Y. Zhou, L. Shao and J. F. Chen, Chem. Eng. J., 2010, 162, 844-851.

19 V. Dhand, L. Soumya, S. Bharadwaj, S. Chakra, D. Bhatt and B. Sreedhar, Mater. Sci. Eng., C, 2016, 58, 36-43.

20 D.-C. Tien, K.-H. Tseng, C.-Y. Liao, J.-C. Huang and T.-T. Tsung, J. Alloys Compd., 2008, 463, 408-411.

21 G. Schmid, Nanoparticles: From Theory to Application, Wiley, 2010.

22 S. M. Dizaj, F. Lotfipour, M. Barzegar-Jalali, M. H. Zarrintan and K. Adibkia, Mater. Sci. Eng., C, 2014, 44, 278-284.

23 J. T. Seil and T. J. Webster, Int. J. Nanomed., 2012, 7, 2767-2781. 24 N. K. R. Bogireddy, H. A. Kiran Kumar and B. K. Mandal, J. Environ. Chem. Eng., 2016, 4, 56-64.

25 N. Kumar, H. Kumar, B. Mann and R. Seth, Spectrochim. Acta, Part A, 2016, 156, 89-97.

26 T. Som and B. Karmakar, Solid State Sci., 2011, 13, 887-895. 27 O. S. Wolfbeis, Chem. Soc. Rev., 2015, 44, 4743-4768.

28 C. S. Tiwary, S. Kashyap, K. Biswas and K. Chattopadhyay, J. Phys. D: Appl. Phys., 2013, 46, 385001.

29 C. S. Tiwary, A. Verma, K. Biswas, A. K. Mondal and K. Chattopadhyay, Ceram. Int., 2011, 37, 3677-3686.

30 A. Verma, K. Biswas, C. Tiwary, A. Mondal and K. Chattopadhyay, Metall. Mater. Trans. A, 2011, 42, 11271137.

31 K. Barai, C. S. Tiwary, P. P. Chattopadhyay and K. Chattopadhyay, Mater. Sci. Eng., A, 2012, 558, 52-58.

32 B. Q. Han, J. Ye, F. Tang, J. Schoenung and E. J. Lavernia, J. Mater. Sci., 2007, 42, 1660-1672.

33 E. J. Lavernia, B. Q. Han and J. M. Schoenung, Mater. Sci. Eng., A, 2008, 493, 207-214.

34 J. Lee, F. Zhou, K. H. Chung, N. J. Kim and E. J. Lavernia, Metall. Mater. Trans. A, 2001, 32, 3109-3115.

35 N. Kumar and K. Biswas, Rev. Sci. Instrum., 2015, 86, 083903. 36 G. K. Williamson and W. H. Hall, Acta Metall., 1953, 1, 22-31. 37 M. S. El-Eskandarany, Mechanical Alloying: Nanotechnology, Materials Science and Powder Metallurgy, Elsevier Science, 2015. 
38 P. Sharma, K. Biswas, A. K. Mondal and K. Chattopadhyay, Scr. Mater., 2009, 61, 600-603.

39 J. Schindelin, C. T. Rueden, M. C. Hiner and K. W. Eliceiri, Mol. Reprod. Dev., 2015, 82, 518-529.

40 M. A. Asoro, P. J. Ferreira and D. Kovar, Acta Mater., 2014, 81, 173-183.

41 C. Goujon, P. Goeuriot, P. Delcroix and G. Le Caër, J. Alloys Compd., 2001, 315, 276-283.

42 G. B. Hoflund, J. F. Weaver and W. S. Epling, Surf. Sci. Spectra, 1994, 3, 163-168.

43 G. B. Hoflund, J. F. Weaver and W. S. Epling, Surf. Sci. Spectra, 1994, 3, 151-156.

44 G. B. Hoflund, Z. F. Hazos and G. N. Salaita, Phys. Rev. B: Condens. Matter Mater. Phys., 2000, 62, 11126-11133.

45 M. Ayyoob and M. S. Hegde, Surf. Sci., 1983, 133, 516-532. 46 M. Ayyoob and M. S. Hegde, Surf. Sci., 1984, 147, 361-376.

47 W. Yan, Z. Zhang, X. Guo, W. Liu and Z. Song, ECS J. Solid State Sci. Technol., 2015, 4, P108-P111.
48 C. S. S. R. Kumar, Mixed Metal Nanomaterials, Wiley, 2009. 49 P. C. Ray, H. Yu and P. P. Fu, J. Environ. Sci. Health, Part C: Environ. Carcinog. Ecotoxicol. Rev., 2009, 27, 1-35.

50 G. E. Dieter, Mechanical metallurgy, McGraw-Hill, 1986.

51 D. A. Wigley, in Mechanical Properties of Materials at Low Temperatures, Springer, US, 1971, ch. 1, pp. 1-46, DOI: 10.1007/978-1-4684-1887-3_1.

52 N. Huang, Y. Xu and D. Jiang, Sci. Rep., 2014, 4, 8.

53 R. J. Hunter, R. H. Ottewill and R. L. Rowell, Zeta Potential in Colloid Science: Principles and Applications, Elsevier Science, 1981.

54 E. J. W. Verwey and J. T. G. Overbeek, Theory of the Stability of Lyophobic Colloids, Dover Publications, 1948.

55 T. K. Sau and A. L. Rogach, Adv. Mater., 2010, 22, 1781-1804. 56 J. Patel, L. Němcová, P. Maguire, W. G. Graham and D. Mariotti, Nanotechnology, 2013, 24, 12. 